Preprint submitted for publication in

The Routledge Research Encyclopaedia of Psychology in the Real World

- Social Change -

\title{
Conflict and Competition
}

\author{
Rima-Maria Rahal ${ }^{1,2} *$ \& Ilja van Beest ${ }^{1}$ \\ 1 Tilburg University \\ 2 Max Planck Institute for Research on Collective Goods
}

* Corresponding Author:

Rima-Maria Rahal Tilburg

University

Prof. Cobbenhagenlaan 225

5037Tilburg, The Netherlands 


\begin{abstract}
Conflict and competition arise when involved parties' preferences and goals collide. This chapter highlights theoretical and empirical perspectives on the emergence and manifestations of conflicts. We outline how conflicts can occur from three perspectives: considering conflicts between individual actors, considering conflicts between individuals in competing groups, and considering conflicts between individuals within their groups. We show how individual-level preferences determine actions taken in dilemma situations in which outcomes are interdependent, leading to cooperative, selfish or competitive behaviour. Further, we summarize key theoretical perspectives about the formation of conflict between groups, and highlight how individual behaviour contributes to such conflicts. We show how individuals may be at odds with other members of their group, experiencing conflict about their relationships and joint tasks. Finally, we outline how coalitions are formed when more than two parties face each other in conflicts. In sum, we consider the potential - both productive and detrimental - that conflict harbours for social exchange.
\end{abstract}

Keywords: conflict; competition; cooperation; social preferences; intergroup; intragroup 


\section{Conceptualizations of Conflict}

Conflict has vast implications for people's lives. In 2016 alone, more than 80.000 people died in armed conflicts worldwide (Uppsala Conflict Data Program, 2016). Conflict between individuals, even about petty disagreements, can put an end to important interpersonal relationships. Conflict within organizations costs billions. On the other hand, conflict can have positive effects, when divergent interests and clashing views lead to creative solutions. Some forms of conflict can also spur parties on to be highly productive. Understanding how and when conflict emerges, how it plays out, and how it can be ameliorated or taken advantage of, are therefore crucial components of psychological inquiry.

Conflict can arise in a variety of settings. The common denominator of situations in which social conflict arises, however, is that at least two parties with potentially conflicting goals are involved. In interpersonal settings, where interactions between individuals are studied, conflict and competition can emerge from the clash of individuals' interests and expectations. In intergroup settings, in addition to the potential for individuals' interests to clash, the interests of superordinate social groups can conflict, causing further potential for conflict and competition.

Finally, sometimes, individuals also find themselves at odds within their groups: individual and group-level goals do not always align, leading to a potential for conflict. However, only the social setting in which conflict arises can differ; the actors themselves differ in how they respond to the challenges of such conflict-laden situations. While some individuals will prioritize their own outcomes, others will deliberately seek to compete and deprive others of their share, while others will cooperate to share resources fairly. Therein, conflict and competition are the results of complex interactions of people and situations. In this chapter, we summarize theoretical and empirical perspectives on understanding conflict, both describing situations in which people are 
confronted with the potential for, and showcasing individual differences, contributing to sparking conflict and competition.

\section{Conflict in Dyadic Decision Settings}

Every day, individuals face countless big and small decisions that harbour potential for conflict and competition. From deciding whether to surprise your spouse with breakfast in bed or sleeping in yourself, to deciding between giving honest feedback during a shopping spree or sparing your friend's feelings, navigating the normal course of life means deciding what to do time and time again in dilemmas that could give rise to conflicts.

The idea that individual decisions in interdependent settings are the source of conflict is embedded in the broader decision-making literature. The roots of the modern investigations of individual choice at the cross-section of psychology and economics lie in the conception of Expected Utility Theory (von Neumann \& Morgenstern, 1944) and Subjective Expected Utility Theory (Savage, 1954). Given the assumptions of well-defined, transitive, continuous and independent preferences, these theories proposed that decision makers would behave as if they maximized their own expected utility over possible outcomes. Decision makers' utility was conceptualized as related to decision makers' desire for certain outcomes, and argued to be captured by observing or predicting choices (Samuelson, 1938). In other words: decision makers, according to Expected Utility Theory, are expected to behave selfishly. This, in turn, can give rise to conflict, when selfish decision makers struggle to secure the best outcomes for themselves.

\section{Conflict in Dyadic Decision Settings: Abstracted Perspectives}

Conflict and competition arise in situations in which outcomes are interdependent. In such interdependent situations, what one can gain also influences what happens to the other (Kollock, 1998). For instance, in common pool dilemmas (Apesteguia \& Maier-Rigaud, 2006; Musgrave, 1959) in which a limited resource is accessed by multiple users (e.g., fish in the oceans), individual 
motives to exploit the resource for one's own benefit (i.e., fish as much as you can, to eat the fish yourself or to sell it) are at odds with others' outcomes (i.e., every fish you fish is a fish that I cannot fish). Further escalating the potential for conflicts, in such dilemmas, selfish motives could even harm the long-term sustainability of the resource (i.e., if we fish above the threshold of fish reproducing to keep the population size intact, fish provision may collapse).

Relatedly, consider the Prisoner's dilemma game (Ledyard, 1995; Figure 1), in which the outcomes of two players are at odds. In this game, decision makers have two options. When both players choose option A (cooperate), each player's outcome is 3 units. When both players choose option B (defect), each player's outcome is 1 unit. When player 1 chooses option A (cooperate) but player 2 chooses option B (defect), player 1 receives nothing, while player B receives 4 units, and vice versa. In this example, assume that decision makers simultaneously decide which option to choose, accumulate payoffs over twenty rounds, and have perfect information (i.e., both players know the number of rounds as well as the contributions of the other player, and that the other player also has all information). Players could try to cooperate, therefore maximizing the joint payoff. However, to maximize individual payoff, a player would want to defect in the last round, to earn the tempting outcome of 4 units in case the other player continues to cooperate, or to avoid remaining empty-handed in this round in case the other player defects. By backward induction (Selten, 1978), this is also true for the second-to-last round, and for all other rounds, making defection the rational course of action (i.e., the subgame perfect equilibrium): full defection should occur in such situations. In other words: individuals would be expected to struggle to secure resources for themselves, thereby forgoing potentially larger outcomes harboured by cooperative strategies. Because defection must be expected from all parties involved, the cooperative potential of a situation cannot be taken advantage of. Cooperation breaks down. 
Psychological research responded to Expected Utility Theory by questioning its descriptive validity and, consequently, its theoretical pre-eminence. This critical attitude also addressed the fundamental assumption of Expected Utility Theory that actors would behave rationally to maximize their own utility. In particular, empirical evidence demonstrated the violation of the maximization of self-interest even in the two-player repeated prisoner's dilemma game, solved by backward induction above: Decision makers do not defect fully (e.g., Chaudhuri, 2011; van Lange, Joireman, Parks, \& van Dijk, 2013). While some decision makers will indeed defect to secure their outcomes, some decision makers cooperate so that cooperation does not break down.

\section{Conflict in Dyadic Decision Settings: Individual Preferences}

Instead of assuming that decision makers will always do what maximizes their own material outcomes, a new strand of the literature considered that others' outcomes also matter to decision makers. By introducing the concept of social preferences, others' outcomes were integrated into decision makers' utility functions (e.g., Axelrod \& Hamilton, 1981; Dawes, 1980; Taylor, 1977). In other words, this line of research began investigating the nature and boundary conditions of prosocial, competitive, and selfish acts. In social decision settings capturing situations in which individuals' choices affect not only themselves but also others, formal models of Utility Theory are used to describe how individuals value certain actions depending on their weighting of outcomes for themselves and others affected (Messick \& McClintock, 1968). An example of such a decision situation is a dictator game (Forsythe, Horowitz, Savin, \& Sefton, 1994), in which one person decides about both her own outcomes and those of a second player. For simplicity, a decomposed dictator game is introduced here (Figure 2). Decision makers are assigned to the role of the dictator or the receiver. The dictator chooses between two options, where one alternative maximizes her own monetary payoff (for example, in Option A, the dictator receives 10 units and the matched player receives 2 units) and the other option benefits the other 
player through a reduction of the dictator's payoff (for example, in Option B, the dictator receives 7 units and the matched player receives 5 units, Figure 2, Example 1). The trade-off between own and others' payoff can be represented as differences in the respective decision weights $w_{O W n}$ and wother:

$$
U=w_{\text {own }} \times(\text { own payoff })+w_{\text {other }} \times(\text { others' payoff }) .
$$

Individuals who positively value their own payoffs and disregard others' outcomes (e.g., $w_{\text {own }}=1$; $w_{\text {other }}=0$ ) are more likely to choose the option maximizing their own payoff, which has a higher utility for them (payoffoption $A=10$, payoff Option $B=7$ ) compared to individuals who assign positive value to both their own and others' payoffs (e.g., $w_{\text {own }}=0.5 ; w_{\text {other }}=0.5$, payoff Option A $=6$, payoff Option $B=6.5)$. Further, consider another variant of this task in which dictators can forgo higher outcomes to avoid that the other player gains payoffs (e.g., in Option A, the dictator receives 10 units and the matched player receives 2 units, whereas in Option C, the dictator receives 9 units and the matched player receives 0.5 units; Figure 2, Example 2). Individuals who positively value their own payoffs and negatively value others' outcomes, so-called competitive players, (e.g., $w_{\text {Own }}$ $\left.=0.5 ; w_{\text {other }}=-0.5\right)$ would be more likely to choose the option that deducts outcomes from the other.

The form in which others' outcomes are integrated into the decision makers' utility function has been the object of several theories of social preferences. Depending on the situations in which behavior is predicted, these theories added different components to the simple utility function suggested above. For instance, the Reciprocity Model (Rabin, 1993) suggested that people will forgo own material outcomes to help or punish others depending on their previous behavior. The Fehr-Schmidt model (Fehr \& Schmidt, 1999) added inequity aversion to the utility function, proposing that some decision makers dislike options where they receive different outcomes than 
others because they are better or worse off, and will make choices to minimize this imbalance. The Boloton-Ockenfels model (Bolton \& Ockenfels, 2000) enriched utility functions by components of equity and reciprocity concerns, as well as competitive behaviour.

Preferences for allocating resources between oneself and another person are thought to have relatively stable, trait-like characteristics (McClintock \& van Avermaet, 1982; Swap \& Rubin, 1983; van Lange, 2000), referred to as Social Value Orientation (SVO, Figure 3, van Lange, 1999; for an overview, see Murphy \& Ackermann, 2013). The weight assigned to own and others' outcomes allows the categorization of decision makers into types. Most commonly, decision makers present with altruistic $\left(w_{\text {own }}=0 ; w_{\text {other }}=1\right)$, prosocial $\left(w_{\text {own }}=0.5 ; w_{\text {other }}=0.5\right)$, individualistic $\left(w_{\text {own }}\right.$ $\left.=1 ; w_{\text {other }}=0\right)$ or competitive $\left(w_{\text {Own }}=0.5 ; w_{\text {other }}=-0.5\right)$ preferences, or intermediate assigned weights (Murphy, Ackermann, \& Handgraaf, 2011), although other weightings of own and others' outcomes are possible (e.g., martyrdom: $w_{\text {own }}=-0.5 ; w_{\text {other }}=0.5$ ). SVO has been shown to be strongly related to the Honesty-Humility factor of personality (Hilbig \& Zettler, 2009), the general tendency to be fair to others (Ashton \& Lee, 2007), and strongly predicts cooperation behaviour in a variety of situations (for a review, see Bogaert, Boone, \& Declerck, 2008): Individualistic and competitive types are less likely to share resources than prosocial and altruistic types (for a metaanalysis, see Balliet, Parks, \& Joireman, 2009), and therefore are more likely at the root of conflict.

\section{Conflict in Group Decision Settings}

Not only the decisions individuals make in dyadic relationships harbour the potential for conflict; individuals in groups and groups as decision making entities can raise conflict (Choi \& Bowles, 2007). For instance, in a time of globalized mobility, strong emphasis on freedom of movement and of rising flows of migration, societies experience new challenges in deciding how to face increasing numbers of immigrants of all types. As the number of newcomers rises, the 
native population's willingness to trust and to approach a foreigner might sink (La Macchia, Louis, Hornsey, \& Leonardelli, 2016). The question of how the native population interacts with newcomers therefore becomes a pressing issue in many societies. In some situations, people might find themselves less likely to help a foreigner. Although the question of how societies face increased immigration is a complex issue, parts of this challenge can be distilled into a question of intergroup interactions: how do members of an ingroup interact with those of an outgroup? What are the driving forces of cooperation and competition in these circumstances? Understanding decisions embedded in a group setting therefore affords opportunities to understand conflict.

\section{Conflict in Group Decision Settings: Empirical Evidence}

Phenomenologically, the influence of group membership on cooperation and competition has been observed in a variety of contexts, indicating that ingroup members are often favoured and outgroups can even be derogated (Hewstone, Rubin, \& Willis, 2002). For instance, outgroup members are trusted less (Glaeser, Laibson, Scheinkman, \& Soutter, 2000) and disfavoured in prosocial decision making (for a meta-analysis, see Balliet, Wu, \& De Dreu, 2014).

A model of how cooperation and competition is affected by group membership was proposed by Chen and Li (2009), in which the weight wother assigned to others' outcomes in decision makers' utility functions is determined by their membership to the ingroup our outgroup $I$, which leads to the (simplified) utility function

$$
U=w_{\text {own }} \times(\text { own payoff })+w_{\text {other }} I_{\times}(\text {others' payoff }) .
$$

In more detail (Chen \& Li, 2009, p. 441), the utility function proposes that the weight placed on others' outcomes depending on their group membership is differently affected when decision makers' own outcomes are larger or smaller than the other persons' outcomes. Supporting this theoretical proposition empirically, decision makers were found to be less charitable to outgroup vs. ingroup members when their own outcomes were larger than the other players', and to 
be more envious of outgroup vs. ingroup members when their own outcomes were smaller than the other players' (Chen \& Li, 2009).

Other investigations of strategic interactions between groups have used different conceptualizations of conflict. For instance, the Intergroup Prisoner's Dilemma (Bornstein, 2003; Figure 4) has been used to study "ingroup love" and "outgroup hate," played by two groups of three players each. Players receive an endowment of 10 units, which will be doubled if they keep them to themselves (i.e., the payoff would be 20 units if all are kept). Alternatively, players can invest (parts of) their endowment in a joint pool. For each unit invested in the joint pool, all ingroup members receive 1 unit, while 1 unit is deducted from all outgroup members. While some players will keep the endowment to themselves, others will invest in the joint pool, effectively contributing to intergroup conflict. When given the option to choose between keeping the endowment (i.e., investing it to benefit the ingroup and hurt the outgroup) or investing it only to benefit the ingroup (Intergroup Prisoner's Dilemma - Maximizing Differences, Halevy, Bornstein, \& Sagiv, 2008; Figure 4), findings suggest that most players prefer benefitting the ingroup only over both benefiting the ingroup and actively harming the outgroup. Conflict between groups, therefore, is not necessarily inevitable. Moreover, whether individuals engage in intergroup conflict also depends on individual differences: while some individuals are universalists and benefit others across the boundaries of groups, others are more parochial, keen to benefit only their ingroup (Aaldering \& Böhm, 2019). It is the latter type of individuals, then, who drive conflict behaviour.

\section{Conflict in Group Decision Settings: Theoretical Perspectives}

Beyond this phenomenological description of how group membership influences cooperation and competition, a number of prominent theories are concerned with explaining human conflict in group settings more broadly (for an overview, see Hogg, 2016). Early theories of 
behaviour in group settings posited that extreme behaviour of benefitting the ingroup and discriminating against the outgroup, resulting in intergroup conflict, would be instigated by an authoritarian personality (Adorno, Frenkel-Brunswik, Levinson, \& Stanford, 1950), and by frustration turning into aggression (Dollard, Miller, Doob, Mowrer, \& Sears, 1939). Taking a context-based approach, the Realistic Group Conflict Theory suggested that intergroup conflict emerged because rivalling groups faced conflicts of interest about their group goals (Sherif, 1966; Sherif, Harvey, White, Hood, \& Sherif, 1961). In economics, labour marked discrimination has been explained using models of taste-based discrimination (i.e., driven by the desire (taste) to avoid hiring minority workers, Becker, 1957) and statistical discrimination (i.e., driven by substitution of individual ability expectations by group average ability, Phelps, 1972).

Contemporary research draws predominantly on three theories to understand intergroup behaviour. Social Identity Theory (Tajfel \& Turner, 1979, 1986) summarizes cognitive, motivational and behavioural influences of group settings. Aiming to explain why people form and maintain groups, Social Identity Theory posits that individuals derive part of their self-concept from their categorization into social groups. Therein, they act not as individuals but as (selfcategorized) members of their groups who aim to achieve positive distinctiveness from other groups (Tajfel \& Turner, 1979). To maintain the ingroup identity and distinctiveness from other groups, discriminatory behaviour - and conflict - emerges. It was argued that behaviour favouring the ingroup and discriminating against the outgroup does not require competition of groups over resources (in contrast to the Realistic Group Conflict Theory), but that mere categorization into groups is a sufficient condition. When decision makers were assigned to minimal groups (i.e., groups with whom the participant shared no common past or future, group members were anonymous, and there was no conflict of interest over group outcomes), their choices demonstrated ingroup favouritism (e.g., Tajfel, 1970; Tajfel, Billig, Bundy, \& Flament, 1971). 
Translating the concepts of social categorization and identity into economic analyses, ingroup favouritism is also captured by Identity Theory (Akerlof \& Kranton, 2000; Bénabou \& Tirole, 2011). The theory holds that social categorization and the resulting identity, such as being an alumnus of a certain college, is associated with specific expectations of behaviour, e.g., for donations to be directed to one's alma mater, not a different college (Akerlof \& Kranton, 2000). Complying with these expectations maximizes utility, whereas deviating from the expectations causes disutility. Therefore, rational decision makers would behave in line with expectations stemming from the social categories to which they belong. The utility function (Akerlof \& Kranton, 2000) holds that utility for the individual $j$ depends on the possible actions a of $j$ and all others $(-j)$, as well as on $j$ 's identity $\left.I_{j}\right)$ :

$$
U_{j}=U_{j}\left(\mathbf{a}_{j}, \mathbf{a}_{-j}, I_{j}\right)
$$

where the identity is represented by

$$
I_{j}=I_{j}\left(\mathbf{a}_{j}, \mathbf{a}_{-j}, \mathbf{c}_{j}, \varepsilon_{j}, \mathbf{P}\right)
$$

The identity depends on $j$ 's assigned social categories $\boldsymbol{c}_{j}$, and on several factors in relation to what is expected of someone belonging to these categories (in which the expectations are captured in $\mathbf{P}$ ): the vector $\varepsilon_{j}$ captures the degree to which $j$ corresponds to the personal characteristics expected, and the degree to which own $\left(\mathbf{a}_{j}\right)$ and others' actions $\left(\mathbf{a}_{-j}\right)$ correspond to the expected actions.

Although these theories assigned great importance to social identity in determining behaviour in broader contexts, the Bounded Generalized Reciprocity Theory (Yamagishi, Jin, \& Kiyonari, 1999) focused on the strategic advantage of group membership for maximizing one's own outcomes. The theory proposed that groups help decision makers form better expectations of others' likelihood to cooperate. Ingroup members can be expected to cooperate more than outgroup members, in turn increasing the likelihood that other ingroup members will cooperate with them. These expectations are based on a system of indirect reciprocity and reputation. The theory 
proposes that ingroup members have a reputation to cooperate that leads other ingroup members to expect them to cooperate. Additionally, reputation promotes cooperation even when there is no direct history of cooperativeness between the same people. Decision makers obtain and maintain the ingroup member status that allows them to benefit from favourable treatment by the ingroup. Consequently, outgroups are trusted less, from which outgroup derogation can follow (for a metaanalysis, see Balliet \& van Lange, 2013).

\section{Conflict in Group Decision Settings: Cognitive Processes}

A socio-cognitive strand of the literature has added the first empirical investigations of the cognitive bases specific to cooperation and defection in group contexts (for a review, see Amodio, 2014). Initial evidence suggests that mental configurations for processing information related to ingroup and outgroup members differ. For example, this evidence shows that outgroup members are evaluated more negatively (Brewer, 1979; LeVine \& Campbell, 1972; Mullen, Brown, \& Smith, 1992; Perdue, Dovidio, Gurtman, \& Tyler, 1990), that people make more positive spontaneous trait inferences about ingroup than outgroup members (Otten \& Moskowitz, 2000), and that positive stereotypes are more rapidly associated with ingroup members (Dovidio, Evans, \& Tyler, 1986). Furthermore, ingroup members are judged to be more similar to oneself than outgroup members even in artificial, minimal groups (Cadinu \& Rothbart, 1996), which is thought to be based on inferences from own traits to the ingroup (Otten \& Epstude, 2006). In short, research finds that people's cognitive landscape is set up in a way that facilitates ingroup-favouring behaviour. 


\section{Conflict of Individuals within their Groups}

In addition to conflicts between individuals or between groups, conflicts may arise between individuals in a group. One way of conceptualizing these conflicts between members of the same group is by considering the object or source of the conflict (Jehn, 1995): relationship conflict stems from interpersonal incompatibilities among group members that may give rise to tension, animosity, and annoyance within one's group whereas task conflict concerns disagreements about the content of and the best way to approach a task the group is working on together. Although it seems intuitive that within a group, any type of conflict would necessarily be bad (in terms of productivity, wellbeing, and other outcomes), empirical evidence suggests that conflict is not necessarily bad and may sometimes even be good. In a seminal study, Karen Jehn (1995) examined over 100 workgroups and management teams in a large trucking company and showed that whether or not conflict was beneficial depended on the type of conflict and the type of task on which the group worked. Specifically, although both task and relationship conflict lowered satisfaction and interpersonal liking, and increased people's intentions to leave the group, task and relationship conflict had different effects on group performance. For routine tasks, disagreements about the tasks were detrimental to the groups' functioning; however, for non-routine, complex tasks, disagreement about the task were not detrimental to the groups' functioning, and could even increase group performance: Task conflict encourages creativity and diversity of opinions which provided it does not result in relationship conflict - increases the quality of the decisions made (Bradley, Postlethwaite, Klotz, Hamdani, \& Brown, 2012; De Dreu, 2006; Farh, Lee, \& Farh, 2010), e.g., by avoiding groupthink (Janis, 1982) and common knowledge effects (Gigone \& Hastie, 1993).

This finding that relationship conflict is detrimental whereas task conflict may have positive or negative effects depending on the complexity of the task the group faces kindled further 
research, summarized in two meta-analyses drawing markedly different conclusions. One metaanalysis summarizing 30 studies on intragroup conflict concluded that mild compared to no conflict could improve group performance, and that severe conflict decreased group performance (De Dreu \& Weingart, 2003). However, there was no evidence that relationship and task conflict led to different outcomes (DeDreu \& Weingart, 2003). In contrast, a meta-analysis summarizing 116 studies (de Wit, Greer, \& Jehn, 2012) found support for Jehn’s (1995) original claim: relationship conflict was associated with worse group outcomes. Further, evidence suggested that task conflict could increase performance, specifically when top management teams faced task conflict, when group performance was assessed in terms of financial performance or decision quality, and when task conflict was accompanied by only little relationship conflict.

Another perspective on sources of intragroup conflict considers individual-level differences between group members, such as gender, education, or personality. Within-group diversity may create faultlines, i.e., dividing lines arising from interindividual differences that may split group members into subgroups (Lau \& Murnighan, 1998). As their physical counterparts, group faultlines may lay dormant and only crack open when triggered. Moderate within-group faultlines have been shown to give rise to less intragroup conflict than strong or weak faultlines (Thatcher, Jehn, \& Zanutto, 2003). In essence, the formation of within-group subgroups brings with it the opportunities and challenges that are associated with higher order groups as well.

\section{Coalitions}

Finally, conflict may occur in situations harbouring the potential for coalition formation. When more than two individuals or groups (hereafter summarized by the term parties) are present and have opposing interests, some may join forces to substantiate their claims and improve their chances of achieving their goals. Coalition formation becomes key when a single party cannot 
achieve its goal without the support of a coalition member. In this case, parties need others to achieve their goals, but must also realize that a coalition could be formed without them.

Coalition formation is often investigated by means of simple weighted majority games. In such games, the parties are informed that they have to pool their resources to be able to decide how to allocate payoffs. Take, for example, the 5(4 32 2) game, in which three parties negotiate about the allocation of a total payoff of 100 units. Party A represents the interests of four people, party B represents three people, and party $\mathrm{C}$ represents two people (Figure 5), and decisions are only possible if a majority of all people agree. People may not leave their parties. The total number of people in this situation is nine, and therefore any combination of at least five people would be able to allocate the payoffs in the way they want. Put differently, party A and B could form an ABcoalition, or party A and C could form an AC-coalition, or party $\mathrm{B}$ and $\mathrm{C}$ could form an $\mathrm{BC}$ coalition. An ABC-coalition could also emerge. What coalition is most likely to emerge? And how would the payoff be allocated, depending on the type of coalition formed?

Several theories address this setup (for an overview, see Kahan \& Rapoport, 2014; Murnighan, 1978; van Beest \& van Dijk, 2007). Here, we consider two perspectives: minimum power theory and minimum resource theory (Gamson, 1961, 1964). Both theories share the assumption that all parties involved want to maximize their own payoffs and not that of others. The second shared assumption is that parties will base the allocations of outcomes to coalition members on distributive fairness norms: If all members of the coalition have contributed equally to the coalition it is assumed that they will ask for an equal share and will be given that share. If some coalition members have contributed more than others, it is assumed that they will ask a share that is proportional to their input. However, these two coalition theories differ in what they consider to be the most appropriate bargaining chip available to the parties. 
Minimum power theory (Gamson, 1964) assumes that both the type of coalition and allocation of payoffs will be based on the relative power of every potential coalition party. Power is based on the Shapley-Shubik index of pivotal power (Shapley \& Shubik, 1954): the relative frequency with which the resources of one party, when added to the resources of another party, convert a non-winning coalition into a winning coalition. In the example above, all possible combinations of parties are coalitions that control a majority of the votes and thus all possible combinations are winning coalitions. Hence, all players are equally powerful, as all players can turn a winning coalition into a losing one equally often. Minimum power theory predicts that parties expect and obtain an equal share of the payoffs in every coalition. In the example above, every party in the $\mathrm{ABC}$-coalition would expect to obtain $1 / 3$ of the total payoff each. In the AB-, AC-, BC-coalition, parties would expect $1 / 2$ of the total payoff, i.e., 50 units each. Assuming that all parties strive to maximize their own outcomes, the prediction is that the grand coalition (ABCcoalition) will not be formed. Instead, it is assumed that every two-party coalition is equally likely to be formed, and that payoffs will be allocated only to those that are in the coalition (50 each) and not to the party excluded from the coalition.

Minimum resource theory (Gamson, 1961) assumes that both the type of coalition and allocation of payoffs will be based on the relative contribution in terms of resources. In the example above, this theory predicts that parties will demand a share of the payoffs in each of these coalitions that is proportional to the number of people that they represent. In the AB-coalition, 7 people are represented, and A would demand $4 / 7$ and B would demand $3 / 7$ of the total payoff. In the AC-coalition, A would demand 4/6 and $\mathrm{C}$ would demand $2 / 6$ of the 100 units. In the BCcoalition, $\mathrm{B}$ would demand $3 / 5$ and $\mathrm{C}$ would demand $2 / 5$ of the 100 units. In the $\mathrm{ABC}$-coalition, $\mathrm{A}$ would demand 4/9, B 3/9, and C 2/9 of the 100 units. As in minimum power theory, the crucial assumption remains that all parties want to maximize their own outcomes. As in minimum power 
theory, a grand coalition (ABC-coalition) is therefore not predicted to be formed. However, different from minimum power theory, minimum resource theory makes specific predictions about what coalition will be formed and how payoffs will be allocated. In the example above, because the BC-coalition maximizes the individual payoff to the party members relative to all other potential coalitions, it is predicted to be formed. Minimum resource theory therefore also outlines that those who bring the most resources to the bargaining table are not necessarily those who walk away with the lion's share of the payoffs. After all, in the example above, party A represented more individuals than any other party. However, because of the entitlement that comes with this relative strength in resources, this party is likely to be excluded from the winning coalitions. By the same token, this suggests an unexpected amount of influence that lies with ostensibly small parties: Because they have relatively little claim to the payoffs, they become attractive coalition partners.

From the perspective of both theories, conflict is sometimes resolved not by a solution that is beneficial to all parties involved, but instead to a subset or coalition. Further, some instances of conflict are resolved not to the benefit of those that appear to have the best cards (i.e., bring the most resources to the table) but instead to the benefit of those that appear to be weak and are equipped with few resources.

Mimicking the insights on dyadic conflict, coalition research has also departed from the general assumption that all players are equally motivated to maximize their own payoffs (van Beest \& van Dijk, 2007). For example, current insights highlight that social preferences of coalition parties may also influence the preference for forming coalitions that maximize the outcome of its members relative to forming coalitions that maximize the outcome of the group. Specifically, parties with a prosocial orientation are more likely form unnecessary large coalitions - i.e, coalitions that obtain more members than would be formally required to win - than parties with a proself orientation (van Beest \& van Dijk, 2007). This finding appears to be stronger in intergroup 
coalitions in which groups of a specific orientation need to form coalitions with other groups than in interpersonal coalition formation in which individuals of a specific orientation form coalition with other individuals (van Beest, Andeweg, Koning, \& van Lange, 2008). Relatedly, coalition formation is not necessarily about decisions that only benefit the coalition members, but coalition members also allocate payoffs to those that are not part of the coalition (van Beest, van Dijk, \& Wilke, 2003).

Take for example a situation in which three parties negotiate about a gain or a loss of 60 units and that any majority of two parties would be able to enforce how these payoffs are allocated to the individual parties. A traditional perspective of coalition formation would assume that the outcome would not depend on the gain vs. loss domain. In the gain situation, this would imply that two parties would form a small coalition, allocating all the payoffs to the coalition members and zero payoffs to the excluded party. In the loss situation, this would imply that two parties form a small coalition, allocate zero losses to themselves and consequently allocate all losses to the excluded party. This, however, is not what is observed empirically in coalition formation. Following the principle of do-no-harm (Baron, 1993, 1995), experiments have shown that coalition bargainers perceive the withholding of gains to excluded parties as less harmful than the assigning of losses to excluded parties. Consequently, although parties were indeed likely to form small twoparty coalitions in the gain domain, they were more likely to form grand three-player coalitions in the loss domain (van Beest, van Dijk, de Dreu, \& Wilke, 2005). In the gain domain, both parties split the gains equally between themselves (in this example, both earn 30 units, leaving the excluded party with 0 units). In the loss domain, all three members of the coalition split the losses equally between themselves (i.e, each party loses 20 units). When there is a conflict about gains, parties may indeed maximize their individual gains. However, if the conflict is framed in terms of 
losses, parties may not be inclined to minimize their own loss, but instead be more concerned with minimizing the losses of others.

In sum, conflicts can also occur in complex situations in which power is distributed asymmetrically between a number of parties. Studying which parties will coalesce, and whether they will exclude others or integrate them in a coalition even when that means reducing their own potential gains, is an important steppingstone to understanding intricate social situations with multiple players.

\section{Discussion and Conclusion}

In this chapter, we have outlined perspectives on understanding how and when conflict emerges, how it plays out, and how it can be ameliorated or put to one's advantage. From smallscale conflict between individuals to large-scale conflicts between groups, or even in cases in which individuals stand in opposition to their groups, conflict captures competing goals and unaligned interests of the involved parties. Conflicts delineate social settings in which opinions, interests, and preferences collide. As such, conflict can be detrimental when the interests of one party are ignored or overruled by those of another. Yet, conflict and competition can also be productive, spurring forward the actors involved to outperform others. Conflict can also give rise to cooperative resolutions -- as in the case of the Prisoner's Dilemma even against predictions of standard theory, or when conflict gives rise to creativity and diversity of opinion. Therefore, conflict is above all a situation that harbours much potential, and can consequently be pivotal for social change. 


\section{References}

Aaldering, H., \& Böhm, R. (2019). Parochial versus universal cooperation: Introducing a novel economic game of within- and between-group interaction. Social Psychological and Personality Science, 1-10. https://doi.org/10.1177/1948550619841627

Adorno, T. W., Frenkel-Brunswik, E., Levinson, D. J., \& Stanford, N. R. (1950). The authoritarian personality. New York, NY, USA: Harper and Row.

Akerlof, G. A., \& Kranton, R. E. (2000). Economics and identity. The Quarterly Journal of Economics, 115, 715-753.

Amodio, D. M. (2014). The neuroscience of prejudice and stereotyping. Nature Reviews Neuroscience, 15, 670-682. https://doi.org/10.1038/nrn3800

Apesteguia, J., \& Maier-Rigaud, F. P. (2006). The role of rivalry: Public goods versus commonpool resources. Journal of Conflict Resolution, 50, 646-663. https://doi.org/10.1177/0022002706290433

Ashton, M. C., \& Lee, K. (2007). Empirical, theoretical, and practical advantages of the HEXACO model of personality structure. Personality and Social Psychology Review, 11, 150-166. https://doi.org/10.1177/1088868306294907

Axelrod, R., \& Hamilton, W. D. (1981). The evolution of cooperation. Science, 211(4489), 13901396. https://doi.org/10.1126/science.7466396

Balliet, D., Parks, C., \& Joireman, J. (2009). Social value orientation and cooperation in social dilemmas: A meta-analysis. Group Processes \& Intergroup Relations, 12, 533-547. https://doi.org/10.1177/1368430209105040

Balliet, D., \& van Lange, P. A. M. (2013). Trust, conflict, and cooperation: A meta-analysis. Psychological Bulletin, 139, 1090-1112. 
Balliet, D., Wu, J., \& De Dreu, C. K. W. (2014). Ingroup favoritism in cooperation: A metaanalysis. Psychological Bulletin, 140, 1556-1581. https://doi.org/10.1037/a0037737

Baron, J. (1993). Heuristics and biases in equity judgements: a utilitarian approach. In B. A. Mellers \& J. Baron (Eds.), Psychological perspectives on justice: Theory and applications (pp. 109-137). New York, NY, USA: Cambridge University Press.

Baron, J. (1994). Blind Justice: Fairness to groups and the do-no-harm principle. Journal of Behavioral Decision Making, 8, 71-83.

Bradley, B. H., Postlethwaite, B. E., Klotz, A. C., Hamdani, M. R., \& Brown, K. G. (2012). Reaping the benefits of task conflict in teams: The critical role of team psychological safety climate. Journal of Applied Psychology, 97, 151-158. https://doi.org/10.1037/a0024200

Becker, G. S. (1957). The economics of discrimination. Chicago, IL, USA: The University of Chicago Press.

Bénabou, R., \& Tirole, J. (2011). Identity, morals, and taboos: Beliefs as assets. The Quarterly Journal of Economics, 126, 805-855.

Bogaert, S., Boone, C., \& Declerck, C. H. (2008). Social value orientation and cooperation in social dilemmas: A review and conceptual model. The British Journal of Social Psychology, 47, 453-480. https://doi.org/10.1348/014466607X244970

Bolton, G. E., \& Ockenfels, A. (2000). ERC: A theory of equity, reciprocity, and competition. The American Economic Review, 90, 166-193.

Bornstein, G. (2003). Intergroup conflict: Individual, group, and collective interests. Personality and Social Psychology Review, 7, 129-145.

Brewer, M. B. (1979). In-group bias in the minimal intergroup situation: A cognitive-motivational analysis. Psychological Bulletin, 86, 307-324. https://doi.org/10.1037/0033-2909.86.2.307 
Cadinu, M. R., \& Rothbart, M. (1996). Self-anchoring and differentiation processes in the minimal group setting. Journal of Personality and Social Psychology, 70, 661-677. https://doi.org/10.1037/0022-3514.70.4.661

Chaudhuri, A. (2011). Sustaining cooperation in laboratory public goods experiments: A selective survey of the literature. Experimental Economics, 14(1), 47-83.

Chen, Y., \& Li, S. X. (2009). Group identity and social preferences. The American Economic Review, 99, 431-457. https://doi.org/10.1257/aer.99.1.431

Choi, J.-K., \& Bowles, S. (2007). The coevolution of parochial altruism and war. Science, 318(5850), 636-640. https://doi.org/10.1126/science.1144237

Dawes, R. M. (1980). Social dilemmas. Annual Review of Psychology, 31, 169-193. https://doi.org/10.1146/annurev.ps.31.020180.001125

De Dreu, C. K. W. (2006). When too little or too much hurts: Evidence for a curvilinear relationship between task conflict and innovation in teams. Journal of Management, 32, 83-107. https://doi.org/10.1177/0149206305277795

De Dreu, C. K. W., \& Weingart, L. R. (2003). Task versus relationship conflict, team performance, and team member satisfaction: A meta-analysis. The Journal of Applied Psychology, 88, 741-749. https://doi.org/10.1037/0021-9010.88.4.741

de Wit, F. R. C., Greer, L. L., \& Jehn, K. A. (2012). The paradox of intragroup conflict: A metaanalysis. The Journal of Applied Psychology, 97, 360-390. https://doi.org/10.1037/a0024844

Dollard, J., Miller, N. E., Doob, L. W., Mowrer, O. H., \& Sears, R. R. (1939). Frustration and agression. New Haven, CT, USA: Yale University Press. 
Dovidio, J. F., Evans, N., \& Tyler, R. B. (1986). Racial stereotypes: The contents of their cognitive representations. Journal of Experimental Social Psychology, 22, 22-37.

https://doi.org/10.1016/0022-1031(86)90039-9

Farh, J.-L., Lee, C., \& Farh, C. I. C. (2010). Task conflict and team creativity: A question of how much and when. Journal of Applied Psychology, 95, 1173-1180. https://doi.org/10.1037/a0020015

Fehr, E., \& Schmidt, K. M. (1999). A theory of fairness, competition, and cooperation. The Quarterly Journal of Economics, 114, 817-868. https://doi.org/10.1162/003355399556151

Forsythe, R., Horowitz, J. L., Savin, N. E., \& Sefton, M. (1994). Fairness in simple bargaining experiments. Games and Economic Behavior, 6, 347-369. https://doi.org/10.1006/game.1994.1021

Gamson, W. A. (1961). An experimental test of a theory of coalition formation. American Sociological Review, 26, 565-573.

Gamson, W. A. (1964). Experimental studies of coalition formation. Advances in Experimental Social Psychology, 1, 81-110.

Gigone, D., \& Hastie, R. (1993). The common knowledge effect: Information sharing and group judgment. Journal of Personality and Social Psychology, 65, 959-974. https://doi.org/10.1037/0022-3514.65.5.959

Glaeser, E. L., Laibson, D. I., Scheinkman, J. A., \& Soutter, C. L. (2000). Measuring trust. Quarterly Journal of Economics, 115, 811-846. https://doi.org/10.1162/003355300554926

Halevy, N., Bornstein, G., \& Sagiv, L. (2008). "In-group love” and “out-group hate” as motives for individual participation in intergroup conflict: A new game paradigm. Psychological Science, 19, 405-411. https://doi.org/10.1111/j.1467-9280.2008.02100.x 
Hewstone, M., Rubin, M., \& Willis, H. (2002). Intergroup bias. Annual Review of Psychology, 53, 575-604. https://doi.org/10.1146/annurev.psych.53.100901.135109

Hilbig, B. E., \& Zettler, I. (2009). Pillars of cooperation: Honesty-humility, social value orientations, and economic behavior. Journal of Research in Personality, 43, 516-519. https://doi.org/10.1016/j.jrp.2009.01.003

Hogg, M. A. (2016). Social identity theory. In S. McKeown, R. Haji, \& N. Ferguson (Eds.), Understanding peace and conflict through Social Identity Theory [Peace Psychology Book Series.] (pp. 3-17). Basel, Switzerland: Springer International Publishing.

Janis, I. L. (1982). Groupthink: Psychological Studies of Policy Decisions and Fiascoes. Boston, MA, USA: Houghton Mifflin.

Jehn, K. A. (1995). A Multimethod Examination of the Benefits and Detriments of Intragroup Conflict. Administrative Science Quarterly, 40, 256-282. https://doi.org/10.2307/2393638

Kahan, J. P., \& Rapoport, A. (2014). Theories of coalition formation. New York, NY, USA: Psychology Press.

Kollock, P. (1998). Social dilemmas: The anatomy of cooperation. Annual Review of Sociology, 24, 183-214. https://doi.org/10.1146/annurev.soc.24.1.183

Komorita, S. S., \& Parks, C. D. (1995). Interpersonal relations: Mixed-motive interaction. Annual Review of Psychology, 46, 183-207.

La Macchia, S. T., Louis, W. R., Hornsey, M. J., \& Leonardelli, G. J. (2016). In small we trust: Lay theories about small and large groups. Personality and Social Psychology Bulletin, 42, 13211334. https://doi.org/10.1177/0146167216657360

Lau, D. C., \& Murnighan, J. K. (1998). Demographic diversity and faultlines: The compositional dynamics of organizational groups. The Academy of Management Review, 23, 325-340. https://doi.org/10.2307/259377 
Ledyard, J. O. (1995). Public goods: A survey of experimental research. In J. H. Kagel \& A. E. Roth (Eds.), The Handbook of Experimental Economics. Princeton, NJ, USA: Princeton University Press.

LeVine, D. T., \& Campbell, R. A. (1972). Ethnocentrism: Theories of conflict, ethnic attitudes, and group behavior. New York, NY, USA: Wiley.

McClintock, C. G., \& van Avermaet, E. (1982). Social values and rules of fairness: A theoretical perspective. In V. J. Derlega \& J. L. Grzelak (Eds.), Cooperation and helping behaviour: Theories and research (pp. 43-71). New York, NY, USA: Academic Press.

Messick, D. M., \& McClintock, C. G. (1968). Motivational bases of choice in experimental games. Journal of Experimental Social Psychology, 4, 1-25. https://doi.org/10.1016/00221031(68)90046-2

Mullen, B., Brown, R., \& Smith, C. (1992). Ingroup bias as a function of salience, relevance, and status: An integration. European Journal of Social Psychology, 22, 103-122. https://doi.org/10.1002/ejsp.2420220202

Murnighan, J. K. (1978). Models of coalition behavior: Game theoretic, social psychological, and political perspectives. Psychological Bulletin, 85, 1130-1153.

Murphy, R. O., \& Ackermann, K. A. (2013). Social value orientation: Theoretical and measurement issues in the study of social preferences. Personality and Social Psychology Review, 18, 1-29. https://doi.org/10.1177/1088868313501745

Murphy, R. O., Ackermann, K. A., \& Handgraaf, M. J. J. (2011). Measuring social value orientation. Judgment and Decision Making, 6, 771-781. https://doi.org/10.2139/ssrn.1804189

Musgrave, R. A. (1959). The Theory of Public Finance: A Study in Public Economy. New York, NY, USA: McGraw-Hill. 
Otten, S., \& Epstude, K. (2006). Overlapping mental representations of self, ingroup, and outgroup: Unraveling self-stereotyping and self-anchoring. Personality and Social Psychology Bulletin, 32, 957-969. https://doi.org/10.1177/0146167206287254

Otten, S., \& Moskowitz, G. B. (2000). Evidence for implicit evaluative in-group bias: Affect-biased spontaneous trait inference in a minimal group paradigm. Journal of

Experimental Social Psychology, 36, 77-89. https://doi.org/10.1006/jesp.1999.1399 Perdue, C. W.,

Dovidio, J. F., Gurtman, M. B., \& Tyler, R. B. (1990). Us and them: Social categorization and the process of intergroup bias. Journal of Personality and Social Psychology, 59, 475486. https://doi.org/10.1037/0022-3514.59.3.475

Phelps, E. S. (1972). The statistical theory of racism and sexism. American Economic Review, 62, 659-661. https://doi.org/10.2307/1806107

Rabin, M. (1993). Incorporating fairness into game theory and economics. The American Economic Review, 83, 1281-1302.

Samuelson, P. A. (1938). A note on the pure theory of consumer's behaviour. Economica, 5(17), 61-71. https://doi.org/10.2307/2548836

Shapley, L. S., \& Shubik, M. (1954). A method for evaluating the distribution of power in a committee system. American Political Science Review, 48, 787-792. https://doi.org/10.2307/1951053

Savage, L. J. (1954). The foundations of statistics. New York, NY, USA: Dover Publications Inc.

Selten, R. (1978). The chain store paradox. Theory and Decision, 9, 127-159. https://doi.org/10.1007/BF00131770

Sherif, M. (1966). In common predicament: Social psychology of intergroup conflict and cooperation. Boston, MA, USA: Houghton Mifflin. 
Sherif, M., Harvey, O. J., White, B. J., Hood, W. R., \& Sherif, C. W. (1961). Intergroup conflict and cooperation: The Robbers Cave experiment. Norman, OK, USA: University Book Exchange.

Swap, W. C., \& Rubin, J. Z. (1983). Measurement of interpersonal orientation. Journal of Personality and Social Psychology, 44, 208-219.

Tajfel, H. (1970). Experiments in intergroup discrimination. Scientific American, 223, 96-102. https://doi.org/10.1038/scientificamerican1170-96

Tajfel, H., Billig, M. G., Bundy, R. P., \& Flament, C. (1971). Social categorization and intergroup behaviour. European Journal of Social Psychology, 1, 149-178. https://doi.org/10.1002/ejsp.2420010202

Tajfel, H., \& Turner, J. (1979). An integrative theory of intergroup conflict. In W. G. Austin \& S. Worchel (Eds.), The social psychology of intergroup relations (pp. 33-47). Monterey, CA, USA: Brooks/Cole.

Tajfel, H., \& Turner, J. C. (1986). The social identity theory of intergroup behavior. Psychology of Intergroup Relations, 5, 7-24. https://doi.org/10.1111/j.1751-9004.2007.00066.x Taylor, M. (1977). Anarchy and cooperation. Political Theory, 5, 271-275.

Thatcher, S. M. B., Jehn, K. A., \& Zanutto, E. (2003). Cracks in diversity research: The effects of diversity faultlines on conflict and performance. Group Decision and Negotiation, 12, 217241. https://doi.org/10.1023/A:1023325406946

Uppsala Conflict Data Program. (2016). Battle-related deaths in state-based conflicts since 1946, by world region. Retrieved October 24, 2019, from Our World in Data website: https://ourworldindata.org/grapher/battle-related-deaths-in-state-based-conflicts-since1946-by-world-region 
van Beest, I., Andeweg, R., Koning, L., \& van Lange, P. A. M. (2008). Do groups exclude others more readily than individuals in coalition formation? Group Processes and Intergroup Relations, 11, 69-81.

van Beest, I., \& van Dijk, E. (2007). Self-interest and fairness in coalition formation: A social utility approach to understanding partner selection and payoff allocations in groups. European Review of Social Psychology, 18, 132-174.

van Beest, I., van Dijk, E., De Dreu, C. K. W. \& Wilke, H. A. M. (2005). Do-no-harm in coalition formation: Why losses inhibit exclusion and promote fairness cognitions. Journal of Experimental Social Psychology, 41, 609-617.

van Beest, I., Wilke, H., \& van Dijk, E. (2003). The excluded player in coalition formation. Personality and Social Psychology Bulletin, 29, 237-247. https://doi.org/10.1177/0146167202239049

van Lange, P. A. M. (1999). The pursuit of joint outcomes and equality in outcomes: An integrative model of social value orientation. Journal of Personality and Social Psychology, 77, 337-349. https://doi.org/10.1037/0022-3514.77.2.337

van Lange, P. A. M. (2000). Beyond self-interest: A set of propositions relevant to interpersonal orientations. European Review of Social Psychology, 11, 297-331. https://doi.org/10.1080/14792772043000068

van Lange, P. A. M., Joireman, J., Parks, C. D., \& van Dijk, E. (2013). The psychology of social dilemmas: A review. Organizational Behavior and Human Decision Processes, 120, 125141. https://doi.org/10.1016/j.obhdp.2012.11.003 von Neumann, J., \& Morgenstern, O. (1944). Theory of games and economic behavior. Princeton, NJ, USA: Princeton University Press. 
Yamagishi, T., Jin, N., \& Kiyonari, T. (1999). Bounded generalized reciprocity: Ingroup boasting and ingroup favoritism. Advances in Group Processes, 16, 161-197. 


\begin{tabular}{|c|c|c|}
\hline $\begin{array}{l}\text { Row Player } \\
\text { Column Player }\end{array}$ & $\begin{array}{c}\text { Option A } \\
\text { (cooperate) }\end{array}$ & $\begin{array}{c}\text { Option B } \\
\text { (defect) }\end{array}$ \\
\hline $\begin{array}{c}\text { Option A } \\
\text { (cooperate) }\end{array}$ & 3 & 0 \\
\hline $\begin{array}{l}\text { Option B } \\
\text { (defect) }\end{array}$ & 4 & 1 \\
\hline
\end{tabular}

Figure 1. Schematic representation of a Prisoner's Dilemma game. 


\begin{tabular}{lcccc}
\hline & Example 1 & Example 2 \\
& Option A & Option B & Option A & Option B \\
\cline { 2 - 5 } & 10 & 7 & 10 & 9 \\
Dictator receives & 2 & 5 & 2 & 0.5 \\
\hline
\end{tabular}

Figure 2. Examples of decomposed dictator games. 


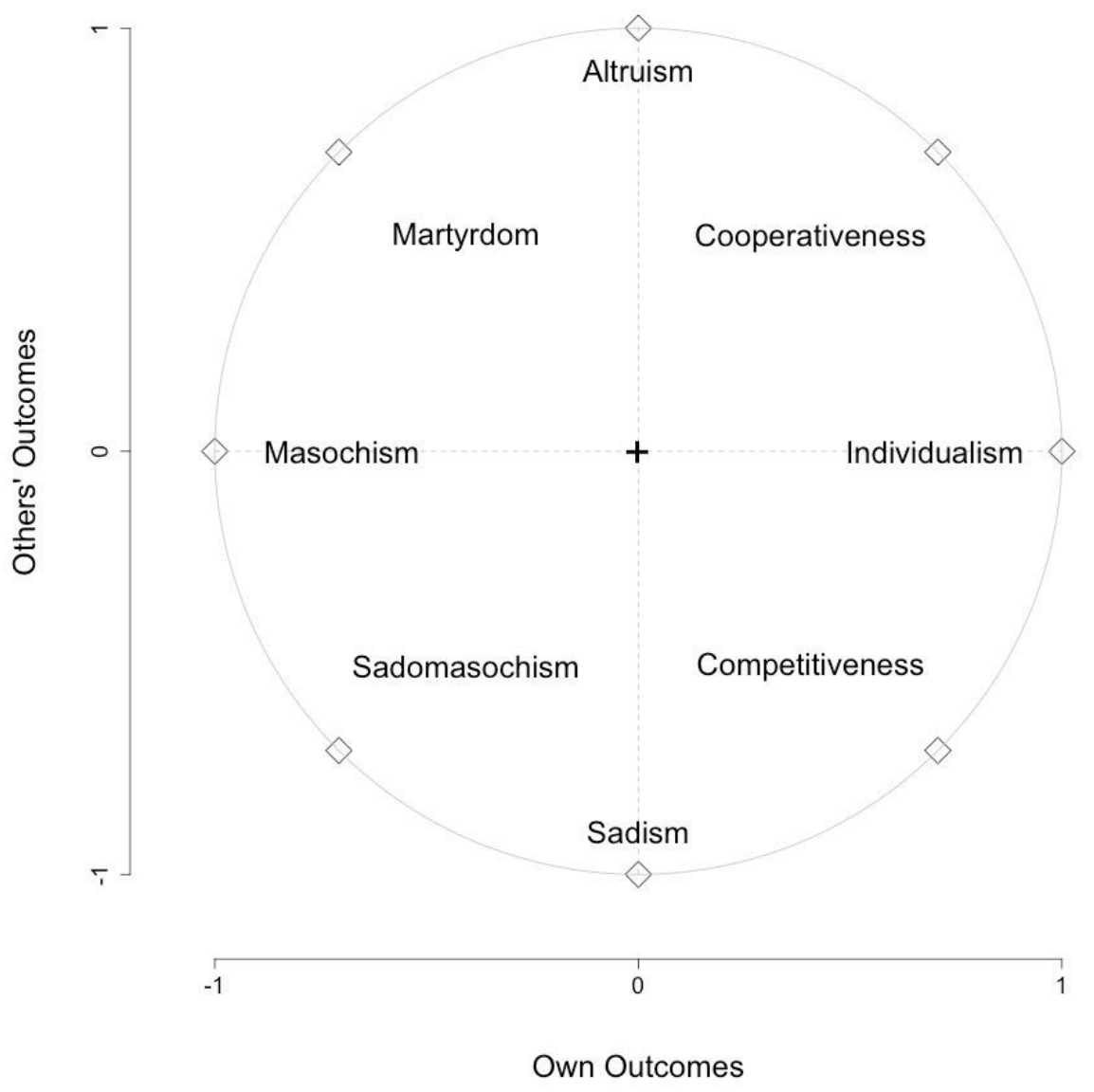

Figure 3. Graphical representation of the dimensions of Social Value Orientation. 


\begin{tabular}{|c|c|c|c|c|c|c|c|}
\hline \multirow[b]{2}{*}{ Game } & \multirow[b]{2}{*}{ Action } & \multicolumn{6}{|c|}{ Consequence for } \\
\hline & & You & $\begin{array}{l}\text { Ingroup } \\
\text { member } \\
2\end{array}$ & $\begin{array}{c}\text { Ingroup } \\
\text { member } \\
3\end{array}$ & $\begin{array}{c}\text { Outgroup } \\
\text { member } \\
1\end{array}$ & $\begin{array}{c}\text { Outgroup } \\
\text { member } \\
2\end{array}$ & $\begin{array}{c}\text { Outgroup } \\
\text { member } \\
3\end{array}$ \\
\hline \multirow[t]{2}{*}{ IPD } & Keep & +10 & 0 & 0 & 0 & 0 & 0 \\
\hline & $\begin{array}{l}\text { Between } \\
\text { group pool }\end{array}$ & $+\mathrm{x}$ & $+x$ & $+\mathrm{x}$ & $-\mathrm{X}$ & $-\mathrm{x}$ & $-\mathrm{x}$ \\
\hline \multirow[t]{3}{*}{ IPD-M D } & Keep & +10 & 0 & 0 & 0 & 0 & 0 \\
\hline & $\begin{array}{l}\text { Between } \\
\text { group pool }\end{array}$ & $+\mathrm{x}$ & $+\mathrm{x}$ & $+x$ & $-\mathrm{x}$ & $-\mathrm{x}$ & $-\mathrm{x}$ \\
\hline & $\begin{array}{l}\text { Within } \\
\text { group pool }\end{array}$ & $+\mathrm{x}$ & $+\mathrm{x}$ & $+x$ & 0 & 0 & 0 \\
\hline
\end{tabular}

Figure 4. Schematic representation of the Intergroup Prisoner's Dilemma (IPD) and the Intergroup Prisoner's Dilemma - Maximizing Differences (IPD-MD) games. 

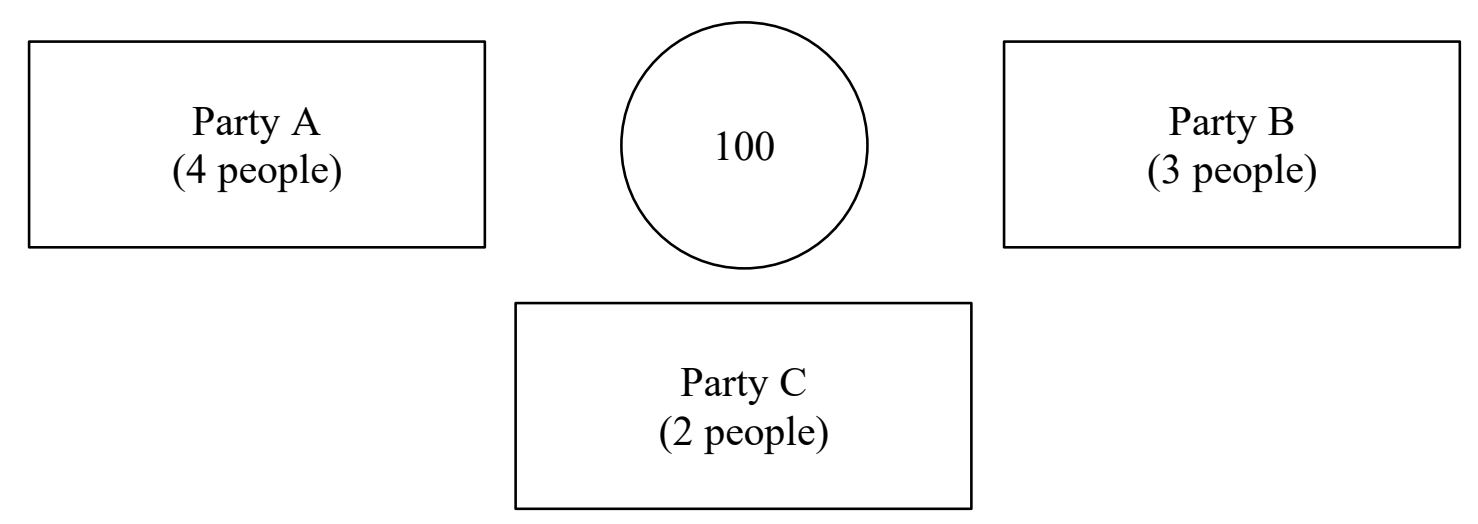

Figure 5. Schematic representation of a coalition game. 